\title{
DURATION OF CHANGE OF PRESSURE IN INTERWALL CAMERA OF MILKING CUP
}

\author{
Vitaly Grinchenko, Gennady Nikitenko, Alexander Lysakov, Evgeny Konoplev \\ Stavropol State Agrarian University, Russia \\ grinchen_ko@mail.ru
}

\begin{abstract}
The article discusses pressure variation in the interwall camera of the milking machine during the milking process. Some patterns are offered for determination of duration of the change of pressure in the interwall camera of a milking cup. A conclusion is drawn for the necessary duration of the change of pressure in the interwall camera of a milking cup. The principle of operation of the modern milking machine is based on periodic interaction of mamillar rubber and vacuum on the animal udder. The duration of the change of pressure in the interwall camera is the main characteristic, which provides an indication of the impact of the milking machine on the animal udder. The modern developments of animal physiology have provided the necessary knowledge on the basis of which the main features of milk processing and the biological requirements for milking are revealed and formulated. Taking into account these features, it is possible to claim that the transition phase from a sucking step to a compression step in the interwall camera of a milking cup will be more smooth and long-lasting. Thus, it is necessary to improve constructions of milking machines for creation of an opportunity to regulate the duration of transitive phases in the interwall camera of a milking cup. It will help avoid the negative impact of the milking machine on the organism of animals in the course of milking that will increase productivity of cows and quality of the received milk.
\end{abstract}

Keywords: milking machine, interwall camera, pulsator.

\section{Introduction}

The main production process in dairy farming is machine milking that displaced hand milking due to reduced work, milk quality improvement, and work organization. Nowadays, machine milking is widely spread not only in big stock breeding complexes using milking machines and robots, but also in small peasant farm enterprises. Despite all advantages machine milking has a range of disadvantages in comparison to hand milking. All milking machines injure the udder resulting in inflammation among cows, garget probability also rises. In Russia it leads to culling every third cow from a herd. Moreover, a milking machine has a "tough" milking mode, it does not provide for physiological make-up of the milk flow process among animals that causes so-called "milking stress" and production loss [1]. That causes reduction in the milk yield, and the cows' genetic potential is not fulfilled. After all, all these disadvantages cause lost profit for farmers and reduce general industry profitability.

\section{Materials and methods}

To remove the existing milking machine disadvantages the department for "Electrical Power Appliance in Farming Industry" of the Stavropol State Agrarian University developed a brand new electrical pulsator [2]. The groundbreaking concept evolves adaptation, i.e. milking machine electrical pulsator adjustment to a new function, namely producing vacuum pulsation corresponding to physiological make-up of the milk flow process among cows due to replacement of soleniod by a new construction linear motor (Fig. 1). This solution allows managing the pressure alteration process duration in the interwall camera of a milking cup.

The breathing process in the interwall camera of milking cups leads to teatcup liner pressing and takes place at rooms' variable volume. This process can be described with the following equation:

$$
\frac{1}{n} \frac{P_{A T M}}{P_{i}} d\left(\frac{P_{i}}{P_{A T M}}\right)=\frac{\mu \varphi S_{3}}{V_{i}} \sqrt{P_{A T M} V_{A T M}}\left(\frac{P_{i}}{P_{A T M}}\right)^{-\frac{1}{n}} d t-\frac{d V_{i}}{V_{i}},
$$

where $n$-polytropic coefficient;

$P_{A T M}$ - pressure in intermural rooms after filling with natural air, $\mathrm{Pa}$;

$P_{i}$ - alternative pressure in intermural rooms, $\mathrm{Pa}$;

$\mu$ - feeding line airflow coefficient with breathing;

$\varphi-$ air flow rate function;

$S_{3}$ - breathing line section area, $\mathrm{m}^{2}$; 
$V_{i}$ - milking machine alternative pressure room and pipe volume at the pressure $P_{i}$ in the interwall camera of a milking cup, $\mathrm{m}^{3}$;

$v_{A T M}$ - air specific volume at the pressure $\mathrm{P}_{\mathrm{ATM}}, \mathrm{m}^{3} \cdot \mathrm{Pa}^{-1}$.

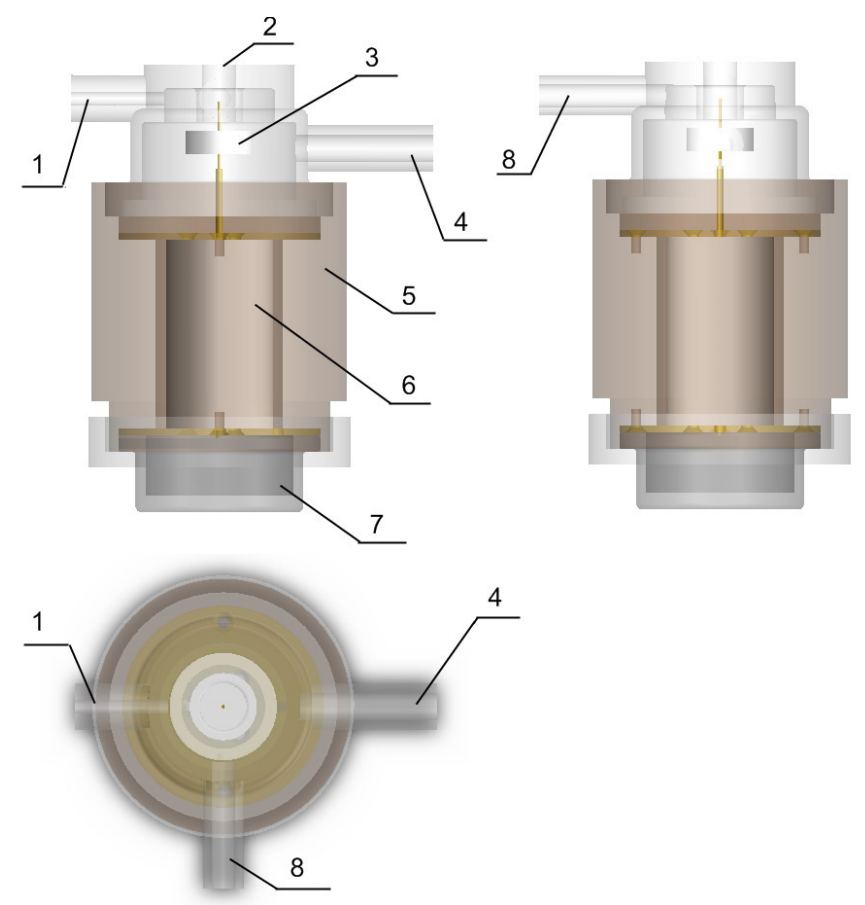

Fig. 1. Developed milking machine electrical pulsator construction: 1 - control port;

2 - atmospheric duct; 3 - valve system; 4 - permanent vacuum connection pipe; 5 - electrical pulsator body; 6 - linear motor; 7 - electrical pulsator lid; 8 - alternate vacuum connection pipe

During the milking machine operation the ambient air temperature and the interwall camera of a milking cup air temperature differ slightly. Breathing time is relatively long, that is why air circulation in the hose can be reputed isothermal. During the isothermal process the polytropic coefficient $n=1$.

The air flow coefficient $\mu$ is determined by the resistance coefficient value from the formula:

$$
\mu=\frac{1}{\sqrt{\varepsilon}}
$$

where $\varepsilon$ - resistance coefficient.

The feeding line resistance coefficient $\varepsilon$ with breathing will be a combination of the resistance coefficients $\varepsilon_{i}$ of the elements in this line:

$$
\varepsilon=\sum_{i} \varepsilon_{i}
$$

If you imagine the feeding line being a sequence of connected flexible ducts having length $l_{T}$ and diameter $D_{T}$, and the collector being a small length duct, the resistance coefficient $\varepsilon$ is equal:

$$
\varepsilon=N\left(\lambda \frac{l_{T}}{D_{T}}+\varepsilon_{C}\right),
$$

where $N$ - number of connected ducts;

$\lambda$ - coefficient depending on the duct tension ratio;

$l_{T}$ and $D_{T}-$ duct length and diameter, m;

$\varepsilon_{C}-$ resistance coefficient in duct joint place.

The duct number $N$, length $l_{T}$ and diameter $D_{T}$ are defined by the number and dimensions of the applied connection pipes. The $\varepsilon_{C}$ coefficient values are to be consulted in reference materials for each element of the milking machine vacuum system [3]. 
Thus, the flow coefficient $\mu$ of the feeding line air at breathing is determined from the following formula:

$$
\mu=\frac{1}{\sqrt{N\left(\lambda \frac{l_{T}}{D_{T}}+\varepsilon_{C}\right)}}
$$

The air discharge function $\varphi$ at isothermal gas flow through local resistance is equal to:

$$
\varphi=\sqrt{\frac{1-\left(\frac{P_{i}}{P_{A T M}}\right)^{2}}{\varepsilon_{K M}-2 \ln \left(\frac{P_{i}}{P_{A T M}}\right)}},
$$

where $\varepsilon_{K M}$ - pulsator valve system resistance coefficient.

At normal conditions the air specific volume is $v_{A T M}=0.773 \mathrm{~m}^{3} \cdot \mathrm{kg}^{-1}$.

In two-phase milking unit intermural rooms the system volume ranges within $V$ and $V_{0}$ proportionally with the pressure ratio $P_{i} / P_{A T M}$ [4], i.e.:

$$
V_{i}=V+\left(V_{0}-V\right) \frac{P_{i}}{P_{A T M}} .
$$

This equation differential is equal to the following:

$$
d V_{i}=\left(V_{0}-V\right) d\left(\frac{P_{i}}{P_{A T M}}\right) .
$$

The engineered milking machine vacuum unit produces nominal discharging $48.0 \cdot 10^{3} \mathrm{~Pa}$, this value correlates with the majority of the modern milking machine vacuum level. Considering the yearly average ambient pressure, that is $98.7 \cdot 10^{3} \mathrm{~Pa}$, the air discharging process in the milking machine ends in the above-critical section at the pressure difference less than 0.528 :

$$
\left(\frac{P_{i}}{P_{A T M}}\right)_{M A X}=\frac{48}{98.7}=0.486<0.528 .
$$

During breathing the cross section area of the atmospheric duct supplying ambient pressure air to intermural rooms gradually grows changing from zero to $S_{3 M A X}$ at $X_{1} \rightarrow M A X$. It happens during the time $t_{C}$ phase $C$. Then the equation describing the breathing process of improved milking machine interwall camera of a milking cup assumes the following form:

$$
\frac{P_{A T M}}{P_{i}} d\left(\frac{P_{i}}{P_{A T M}}\right)=\frac{\mu \varphi S_{3} \sqrt{P_{A T M} v_{A T M}} d t}{\frac{P_{i}}{P_{A T M}}\left(V+\left(V_{0}-V\right) \frac{P_{i}}{P_{A T M}}\right)}-\frac{\left(V_{0}-V\right) d\left(\frac{P_{i}}{P_{A T M}}\right)}{V+\left(V_{0}-V\right) \frac{P_{i}}{P_{A T M}}} .
$$

After simplification we have the following:

$$
V d\left(\frac{P_{i}}{P_{A T M}}\right)+2\left(V_{0}-V\right) \frac{P_{i}}{P_{A T M}} d\left(\frac{P_{i}}{P_{A T M}}\right)=\mu \varphi S_{3} \sqrt{P_{A T M} v_{A T M}} d t .
$$

We integrate it from 1 to the pressure ratio value, taking into account the area $S_{3}$ changing pattern, we have the following: 


$$
\begin{aligned}
& \int_{1}^{\frac{P_{i}}{P_{A T M}}}\left(V d\left(\frac{P_{i}}{P_{A T M}}\right)+2\left(V_{0}-V\right) \frac{P_{i}}{P_{A T M}} d\left(\frac{P_{i}}{P_{A T M}}\right)\right)= \\
& =\int_{0}^{t} \mu \varphi \frac{\pi}{4}\left(D_{A}+\frac{X_{1}}{2 \sqrt{3}}\right) \sqrt{\left(D_{A}-\frac{X_{1}}{2 \sqrt{3}}\right)^{2}+\left(\frac{X_{1}}{2}\right)^{2}} \sqrt{P_{A T M} v_{A T M}} d t .
\end{aligned}
$$

The solution is the following:

$$
\begin{aligned}
& V\left(\left(\frac{P_{i}}{P_{A T M}}\right)_{M A X}-\frac{P_{i}}{P_{A T M}}\right)+\left(V_{0}-V\right)\left(\left(\frac{P_{i}}{P_{A T M}}\right)_{M A X}^{2}-\left(\frac{P_{i}}{P_{A T M}}\right)^{2}\right)= \\
& \left.=\frac{\pi \mu \varphi \sqrt{P_{A T M} v_{A T M} t}}{8 \sqrt{3} X_{1}}\left[\frac{1}{\sqrt{3}}\right]\left[\left(D_{A}-\frac{X_{1}}{2 \sqrt{3}}\right)^{2}+\left(\frac{X_{1}}{2}\right)^{2}\right]^{\frac{3}{2}}-D_{A}^{3}\right)+ \\
& +\frac{15 D_{A}}{8 X_{1}}\left(\frac{2 X_{1}^{2}}{3}-\frac{D_{A} X_{1}}{\sqrt{3}}\right) \sqrt{\left(D_{A}-\frac{X_{1}}{2 \sqrt{3}}\right)^{2}+\left(\frac{X_{1}}{2}\right)^{2}}+\frac{5 \sqrt{3} D_{A}^{3}}{8}+ \\
& \left.+\frac{15 \sqrt{3} D_{A}^{3}}{16} \ln t\left(\ln \left[1-\frac{D_{A} \sqrt{3}}{2 X_{1}}+\frac{\sqrt{3}}{X_{1}} \sqrt{\left(D_{A}-\frac{X_{1}}{2 \sqrt{3}}\right)^{2}+\left(\frac{X_{1}}{2}\right)^{2}}\right]-\ln \frac{D_{A} \sqrt{3}}{2 X_{1}}\right)\right] .
\end{aligned}
$$

Using the properties of logarithms, let us represent a diminution of natural logarithms in the form of specific logarithms; we get the following argument of the logarithm:

$$
\frac{1-\frac{D_{A} \sqrt{3}}{2 X_{1}}+\frac{\sqrt{3}}{X_{1}} \sqrt{\left(D_{A}-\frac{X_{1}}{2 \sqrt{3}}\right)^{2}+\left(\frac{X_{1}}{2}\right)^{2}}}{\frac{D_{A} \sqrt{3}}{2 X_{1}}},
$$

that at any values $D_{A}$ and $X_{1}$ in $\mathrm{m}$ tends to 1 . As $\ln 1=0$, then the summand

$$
\frac{15 \sqrt{3} D_{A}^{3}}{16} \ln t\left(\ln \left[1-\frac{D_{A} \sqrt{3}}{2 X_{1}}+\frac{\sqrt{3}}{X_{1}} \sqrt{\left(D_{A}-\frac{X_{1}}{2 \sqrt{3}}\right)^{2}+\left(\frac{X_{1}}{2}\right)^{2}}\right]-\ln \frac{D_{A} \sqrt{3}}{2 X_{1}}\right)
$$

can be neglected, then the congruence (13) after simplification takes the following form:

$$
\begin{aligned}
& \left(\left(\frac{P_{i}}{P_{A T M}}\right)_{M A X}-\frac{P_{i}}{P_{A T M}}\right)\left[V+\left(V_{0}-V\right)\left(\left(\frac{P_{i}}{P_{A T M}}\right)_{M A X}+\frac{P_{i}}{P_{A T M}}\right)\right]= \\
& =\frac{\pi \mu \varphi \sqrt{P_{A T M} v_{A T M} t}}{24 X_{1}}\left[\left[\left(D_{A}-\frac{X_{1}}{2 \sqrt{3}}\right)^{2}+\left(\frac{X_{1}}{2}\right)^{2}\right]^{\frac{3}{2}}+\right. \\
& \left.+\frac{1}{8}\left(10 \sqrt{3} D_{A} X_{1}-15 D_{A}^{2}\right)\left[\left(D_{A}-\frac{X_{1}}{2 \sqrt{3}}\right)^{2}+\left(\frac{X_{1}}{2}\right)^{2}\right]^{\frac{1}{2}}+7 D_{A}^{3}\right) .
\end{aligned}
$$


Having made mathematical transformations with consideration for interrelation of the atmospheric duct diameter $D_{A}$ and interchange of $X_{1}$, we have the following:

$$
\begin{aligned}
& \left(\left(\frac{P_{i}}{P_{A T M}}\right)_{M A X}-\frac{P_{i}}{P_{A T M}}\right)\left[V+\left(V_{0}-V\right)\left(\left(\frac{P_{i}}{P_{A T M}}\right)_{M A X}+\frac{P_{i}}{P_{A T M}}\right)\right]= \\
& =\frac{\pi \mu \varphi \sqrt{P_{A T M} v_{A T M}} X_{1}^{2}\left(7.418-1.797 X_{1}^{2}\right) t}{24} .
\end{aligned}
$$

From (17) we express the breathing process duration $t_{C}$, that goes on during the phase $C$ :

$$
t_{C}=\frac{24\left(\left(\frac{P_{i}}{P_{A T M}}\right)_{M A X}-\frac{P_{i}}{P_{A T M}}\right)\left[V+\left(V_{0}-V\right)\left(\left(\frac{P_{i}}{P_{A T M}}\right)_{M A X}+\frac{P_{i}}{P_{A T M}}\right)\right]}{\pi \mu \varphi \sqrt{P_{A T M} v_{A T M}} X_{1}^{2}\left(7.418-1.797 X_{1}^{2}\right)} .
$$

\section{Results and discussion}

The developed pulsator is characterized by the presence of the upper and lower valves, which, when the linear electric drive operates, open and close the atmospheric and vacuum channels, which results in soft enveloping of the nipples of the animal with rubber, excluding the reverse milk current when changing the sucking cycle by compression stroke and injuring the nipples of the udder of cows [2]. According to (18) the phase $C$ duration depends not only on the interwall camera of a milking cup volume and discharging system dimensions, but also on the pulsator poppet valve opening regularity, managing of which according to the present research is performed by the linear motor.

\section{Conclusions}

1. The regularities of the change in the duration of the filling processes of the interstitial chambers of the teat cups with atmospheric air have been obtained, according to which the movement of the cone-shaped valve of the electric pulsator has the greatest influence on the duration of the transition process from the sucking stroke to the compression stroke.

2. It will become possible to study the transient process influence in the interwall camera of a milking cup on the cow production in greater detail, develop milking modes with pulsations corresponding to the milk flow process physiological make-up.

3. End consumers will get more functional milking machines for less money that will reduce animals' injuring, garget incidents, increase dairy cow production that will contribute to the state food security.

\section{References}

1. Kapustin I.V., Grinchenko V.A., Gritsay D.I., Kapustina E.I. The physiological requirements for the engineering of milking machines to reduce mastitis, Research Journal of Pharmaceutical, Biological and Chemical Sciences. 2016. Vol. 7, Is. 2. pp. 338-343.

2. Grinchenko V.A., Nikitenko G.V., Lysakov A.A., Konoplev E.V., 2016. Milking machine with electropulsator. Engineering forRural Development, Latvia University of Agriculture, pp. 230-235.

3. Juricek J. Overovanie funkcie elektromagnetickyh pulzatorov, Polnohospodarstvo. - 1991. - T. 37. - pp. 263-268.

4. Manus sentralpulsering for mjolkestall, Provemelding Norges landbrukshogskole. Inst. for tekn. fag. - Norge, 1992. - Vol. 673. -5 p. 